\title{
A descriptive report of the selenium distribution in tissues from pigs with mulberry heart disease (MHD)
}

Marianne Oropeza-Moe ${ }^{1 *}$ (D) Michaela Falk², Marie Vollset ${ }^{3}$, Helene Wisløff $^{4}$, Aksel Bernhoft $^{4}$, Tore Framstad ${ }^{5}$ and Brit Salbu ${ }^{3}$

\begin{abstract}
Background: Mulberry Heart Disease (MHD) is a condition affecting mainly young pigs in excellent body condition. Feed efficient pigs showing high average daily gains are more likely to be affected. MHD has been described as a challenge in Norwegian pig production over the last decade despite abundant supplies of vitamin E, and selenium (Se) close to the upper limits set by the EU. From 2015 to 2017, samples from documented MHD field cases were collected and compared with controls regarding post mortem findings and Se concentrations in numerous internal and external organs were determined in order to characterize the Se distribution, and to identify any differences between MHD cases and controls.
\end{abstract}

Case presentation: Eight MHD cases from commercial farms and a pet pig producer located in the South West and East of Norway, and three control animals originating from these farms were included in this study. MHD cases and controls were weaned pigs with an average bodyweight (BW) of $17 \mathrm{~kg}$ (range 9 to $46 \mathrm{~kg}$ BW), with the exception of one pet piglet (Mangalica, $6 \mathrm{~kg} \mathrm{BW}$ ) that had only received sow milk. Selenium was determined in samples from the cardiovascular, digestive, immune, endocrine, integumentary, muscular, respiratory and urinary systems using inductively coupled plasma mass spectrometry (QQQ ICP-MS). All pigs with MHD suffered sudden deaths. Control animals were euthanized without being bled prior to necropsy and sampling. Significantly different mean Se concentrations between MHD cases and controls were found in cardiac samples as well as almost all skeletal muscles $(P<0.05)$. Based on the samples from ten different muscles (except the cardiac samples), mean Se concentrations in MHD cases were $0.34(0.01) \mathrm{mg} / \mathrm{kg}$ DM compared with $0.65(0.02) \mathrm{mg} / \mathrm{kg}$ DM in control pigs $(P<0.0001)$. In cardiac samples, mean Se concentrations from MHD cases were $0.87(0.02) \mathrm{mg} / \mathrm{kg}$ DM vs. $1.12(0.04)$ $\mathrm{mg} / \mathrm{kg} \mathrm{DM}(P<0.0001)$. Additionally, significantly lower Se concentrations compared with controls were found in the liver as well as the caecum, duodenum, gastric ventricle, jejunum, kidney, skin and thymus samples.

Conclusions: Based on the present work, the current common practice regarding tissue analyses in MHD cases could be refined to include other organs than liver and heart. The evident differences in mean Se concentrations in 9 out of 10 samples from the muscular system, could make such samples relevant for complementary measurements of Se concentrations to help confirm the MHD diagnosis. We find it interesting that although our limited number of sampled pigs are different in terms of genetics, size and feeding regimes, the variation of Se concentrations in a given organ was low between MHD cases. Since this report includes a limited number of MHD cases and controls, our results should be corroborated by a controlled, larger study.

Keywords: Mulberry heart disease, Skeletal muscle, Liver, Cardiac, Muscular, Gastrointestinal, Selenium, Distribution

\footnotetext{
* Correspondence: marianne.oropeza-moe@nmbu.no

'Department of Production Animal Clinical Sciences, Norwegian University of

Life Sciences, 4325 Sandnes, Norway

Full list of author information is available at the end of the article
}

(c) The Author(s). 2019 Open Access This article is distributed under the terms of the Creative Commons Attribution 4.0 International License (http://creativecommons.org/licenses/by/4.0/), which permits unrestricted use, distribution, and reproduction in any medium, provided you give appropriate credit to the original author(s) and the source, provide a link to the Creative Commons license, and indicate if changes were made. The Creative Commons Public Domain Dedication waiver (http://creativecommons.org/publicdomain/zero/1.0/) applies to the data made available in this article, unless otherwise stated. 


\section{Background}

Selenium (Se) deficiency involved in fatal cardiomyopathy is well known in pigs [1-3]. Se deficiency probably causes uncompensated oxidative stress leading to cellular damage, often resulting in death [3]. The importance of Se and selenoproteins in muscle tissue physiology is well documented. Studies have shown that the gene expression, plasma and tissue concentrations of selenoprotein $\mathrm{W}$ and selenoprotein $\mathrm{P}$ as well as glutathione peroxidase activity, are higher in Se-supplemented than Se-deficient animals [4-8].

Mulberry heart disease (MHD) is a peracute to acute condition, appearing mainly in pigs of two to four months of age. It has, however, been observed in pigs as young as three weeks. Typically pigs in excellent body condition are found dead. The principal gross lesions in pigs succumbing to MHD are straw-colored fluid in the pleural cavity, transudate with fibrin in the pericardium and edematous lungs. The myocardium appears mottled due to transmural hemorrhage and pale necrotic areas. Oxidative stress causes oxidative modifications of myofilament proteins like actin, titin and myosin and can thereby impair the contractility of myocytes [9]. The above mentioned alterations in myocytes combined with macroscopic and microscopic lesions of MHD cases strongly suggest ventricular dysrhythmia followed by acute heart failure. The diagnosis of MHD can be confirmed when the following microscopic heart lesions are observed: In acute cases interstitial hemorrhage is the main lesion, whereas in less acute cases degeneration and necrosis of myofibers, sometimes with mineralization, are observed. [10].

Tremendous advancement within molecular biology and genomics over the last decades, e.g. the sequencing of the porcine genome [11], has facilitated development and improvement of sophisticated research methods and technology. The added value of DNA information to breeding values can now contribute to rapid genetic progress [12]. The breeding goals of most pig breeding companies globally include lean growth efficiency, reduced feed intake per kg growth and reduced backfat [13-17].

The number of publications on MHD and Se concentrations in porcine tissues in peer reviewed literature is limited, and the majority of the existing reports are more than fifteen years old [10, 18-21]. Some of these reports have stated that tissue concentrations of Se in heart and liver samples are within the normal range in MHD cases $[10,18,19]$. Unpublished cases from Norway over the last five years support these statements, also with results based on Se concentrations in liver samples. Nevertheless MHD cases cease to occur in affected herds after Se supplementation, either by injection treatments with Se or feed additives containing Se and vitamin E.
This study was carried out on MHD cases and control pigs reared under field conditions, in order to characterize the Se distribution in multiple tissues of MHD cases and controls prior to and after weaning. To the authors' knowledge, this is the first report to describe the Se distribution in numerous internal and external organs of pigs diagnosed with MHD.

\section{Case presentation}

The pigs included in this study were submitted for post mortem examinations to the Norwegian Veterinary Institute in Oslo and Sandnes and the Norwegian University of Life Sciences in Sandnes between 2015 and 2017. The pigs originated from five commercial piglet producing farms (Farms 1 to 5) and one pet pig producer (Farm 6) located in the counties of Oppland and Rogaland in Norway (Table 1). The piglet from the latter farm had only been fed sows' milk.

The Se added to the compound feedingstuffs provided at the farms was sodium selenite at levels between $0.33 \mathrm{mg} / \mathrm{kg}$ and $0.40 \mathrm{mg} / \mathrm{kg}$ feed. The amount of alpha-tocopherol (vit E) added to the feed was between $100 \mathrm{mg} / \mathrm{kg}$ to $200 \mathrm{mg} / \mathrm{kg}$ feed. Non-supplemented raw materials used to produce compound feedingstuffs for pigs with Norwegian origin contain negligible Se levels around $0.05 \mathrm{mg} / \mathrm{kg}$ [4]. The feed composition of the feed provided at the different farms is listed in Table 2.

MHD cases and control pigs underwent complete post mortem examinations. Pigs included as MHD cases had died suddenly and showed both typical macroscopic (Fig. 1) and (Fig. 2) microscopic lesions. Control pigs were selected from two of the farms submitting MHD cases. These pigs had the same genetic background and similar size as the confirmed MHD cases. Control animals were pigs showing good average daily gain compared to their littermates and other litters of the same batch, and they had not been treated due to sickness. Control animals showed no signs of pathological lesions when undergoing post mortem examinations.

A sampling protocol was elaborated to ensure a standardized sampling procedure for each organ. Tissue samples from the cardiovascular, digestive, immune, endocrine, integumentary, nervous, muscular, reproductive, respiratory and urinary systems were obtained (Table 3). Samples were dried with paper sheets to remove surplus blood. Intestinal samples were rinsed with water to remove intestinal contents prior to drying off with paper.

From all animals, tissue samples from the myocardium were examined histologically. Additionally, samples from tissues showing lesions were examined. Tissue samples of approximately $15 \times 10 \times 5 \mathrm{~mm}$ were fixed in $4 \%$ formaldehyde for one week and then dehydrated in graded ethanols and paraffin embedded. Sections $(4 \mu \mathrm{m})$ were mounted on slides and stained with hematoxylin and 
Table 1 Description of included Mulberry Heart Disease (MHD) and control pigs in the case study

\begin{tabular}{|c|c|c|c|c|c|c|c|c|c|}
\hline No. & MHD/ Control & Farm & Sex & Age (weeks) & Bodyweight (kg) & Genetics & Iron treatment* & $\begin{array}{l}\text { Sodium selenite } \\
(\mathrm{mg} / \mathrm{kg})\end{array}$ & $\begin{array}{l}\text { Alpha-tocopherol } \\
\text { (mg/ kg) }\end{array}$ \\
\hline 1 & MHD & 1 & C & 14 & 45.0 & $\mathrm{HHZL}$ & Oral paste/ iron-enriched peat & 0.40 & 175.00 \\
\hline 2 & $\mathrm{MHD}$ & 2 & $\mathrm{~F}$ & 6 & 12.0 & HHZL & Injection & 0.39 & 180.00 \\
\hline 3 & MHD & 2 & C & 6 & 16.0 & $\mathrm{HHZL}$ & Injection & 0.39 & 180.00 \\
\hline 4 & $\mathrm{MHD}$ & 3 & C & 6 & 11.0 & LLLL & Injection & 0.33 & 100.00 \\
\hline 5 & MHD & 3 & $\mathrm{~F}$ & 6 & 10.0 & LLLL & Injection & 0.33 & 100.00 \\
\hline 6 & $\mathrm{MHD}$ & 4 & C & 6 & 9.0 & DDLL & Oral paste/ iron-enriched peat & 0.40 & 162.00 \\
\hline 7 & MHD & 5 & C & 8 & 14.0 & DDZL & Oral paste/ iron-enriched peat & 0.33 & 100.00 \\
\hline 8 & MHD & 6 & $\mathrm{~F}$ & 6 & 6.0 & Mangalica & Injection & Sow milk & \\
\hline 1 & Control & 1 & C & 14 & 42.0 & $\mathrm{HHZL}$ & Iron paste and & 0.40 & 175.00 \\
\hline 2 & Control & 2 & C & 6 & 18.0 & $\mathrm{HHZL}$ & Iron injection & 0.39 & 180.00 \\
\hline 3 & Control & 2 & $\mathrm{~F}$ & 7 & 25.0 & HHZL & Iron injection & 0.39 & 180.00 \\
\hline
\end{tabular}

Female (F) and castrated (C) pigs in this study originated from five commercial pig producing farms and one pet farmer. The pigs included in this study were both male and female pigs between six and fourteen weeks old. The Se source used in the complete feed was sodium selenite (NaSe) and added levels of NaSe were between 0.33 and $0.40 \mathrm{mg} / \mathrm{kg}$ feed. The vitamin E (vit E) source was alpha tocopherol and added levels were between $100.00 \mathrm{and} 200.00 \mathrm{mg} / \mathrm{kg}$ feed. The grower-finisher pigs from Farm 1 were fed liquid feed in combination with whey from approximately $30 \mathrm{~kg}$ bodyweight or approximately ten weeks of age. *Iron treatment of the piglets was applied within the first four days of life, either by injecting $200 \mathrm{mg}$ subcutaneously or providing $300 \mathrm{mg}$ of bioavailable iron per os combined with iron-enriched peat until weaning

eosin (HE). Light microscopic examination was conducted to specifically assess for myocardial lesions compatible with MHD. Pigs with characteristic macroscopic lesions combined with the following myocardial histopathology were considered MHD cases: Severe subepicardial and myocardial hemorrhages, swollen cardiac myofibers with loss of cross striations, and hypereosinophilic myofibers with pyknotic nuclei.

Samples of different tissues were collected at the same localization from each animal, both MHD cases and controls. Approximately $50 \mathrm{mg}$ of tissue for ICPMS analysis were placed in $1.8 \mathrm{~mL}$ cryotubes (Nunc Cryotube $^{\mathrm{rm}}$, Sigma-Aldrich, Leirdal, Norway) and stored at $-20{ }^{\circ} \mathrm{C}$ until ICP-MS analysis. From the cardiac muscle, transmural samples were obtained from the center of the right and left free ventricular wall. Additionally, a transmural sample from the center of the septum was obtained. The gastric ventricle was sampled at the Curvatura major. Samples from the gastrointestinal tract were isolated from the proximal section of each intestinal region. From the liver, tissue was sampled from the lobe adjacent to the gallbladder. The splenic lobe of the pancreas was sampled. Both parathyroid glands were collected. Samples from the spleen, thymus, thyroid gland, skeletal muscles and kidney were obtained from the center of the organs. The lung was sampled from the right or left caudal lobes. The skin and bristles were sampled from the left or right lateral abdominal flank. Claw samples were from the distal tip of the left or right hoof wall.

A total of five to eight samples per tissue were analyzed for their total Se concentration (MHD cases) and compared to Se levels in samples from the three control animals. The concentrations of Se in collected organs were determined using inductively coupled plasma mass spectrometry (Agilent 8800 QQQ ICP-MS, Japan) at the Norwegian University of Life Sciences (NMBU/MINA). The organs were weighed, freeze-dried, transferred to acid cleaned Teflon tubes, and then weighed once more. The samples were added $2 \mathrm{ml}$ water, $60 \mathrm{ng} 74 \mathrm{Se}$ (enriched to $99.9 \%$ ) as internal standard and $1.5 \mathrm{~mL}$ conc HNO3 (ultrapure quality). The samples, CRM and blanks were digested in an UltraClave and/or UltraWave from Milestone at $260^{\circ} \mathrm{C}$ for about $20 \mathrm{~min}$. After digestion, all samples were diluted to $15 \mathrm{ml}$ prior to measurements [22]. Bovine Liver 1577c served as CRM. Limit of detection (LOD) and limit of quantification (LOQ) were calculated, 3 and 10 times respectively the standard deviation of the method blanks. In the present work LOD $0.005 \mathrm{mg} \mathrm{Se} / \mathrm{kg}$, LOQ $0.016 \mathrm{mg} \mathrm{Se} / \mathrm{kg}$.

Microbiologic examination was conducted on selected tissues from all animals. Specimens were inoculated on sheep blood agar for $48 \mathrm{~h}$ at $37^{\circ} \mathrm{C}$ and $5 \% \mathrm{CO}_{2}$. No bacterial growth was identified from any of the specimens tested.

All data were exported to Excel (Microsoft Corporation, Redmond, Washington) and then imported into JMP $^{\circ}$ Pro 14.0.0 (SAS Institute Inc., Cary, NC 2751, USA) for statistical analyses. Normality of data was tested by the Shapiro-Wilk test and homogeneity of variance. Differences between groups were analyzed by 1-way analysis of variance with concentrations of Se as the dependent variable and the animals' status (MHD or control) as the independent variable. The farm, feed, sex and age were used as covariates. The p-level was set to 0.05 . Potential outliers were 
Table 2 Feed composition

\begin{tabular}{|c|c|c|c|c|c|c|c|c|}
\hline \multirow[t]{2}{*}{$\%$} & \multicolumn{2}{|c|}{ Farm $1 *$} & \multicolumn{2}{|l|}{ Farm 2} & \multirow{2}{*}{$\begin{array}{l}\text { Farm } 3 \\
\text { MHD4 MHD5 }\end{array}$} & \multirow{2}{*}{$\begin{array}{l}\text { Farm } 4 \\
\text { MHD6 }\end{array}$} & \multirow{2}{*}{$\begin{array}{l}\text { Farm } 5 \\
\text { MHD7 }\end{array}$} & \multirow{2}{*}{$\begin{array}{l}\text { Farm } 6 \\
\text { MHD8 }\end{array}$} \\
\hline & MHD1 & C1 & MHD2/ MHD3 & $\mathrm{C} 2 / \mathrm{C} 3$ & & & & \\
\hline Fishmeal LT-94 & & & 7.00 & 7.00 & & 5.00 & & Sow milk \\
\hline Barley & 35.48 & 32.16 & 16.80 & 10.00 & 43.13 & 22.60 & 27.71 & \\
\hline Soybean cake flour & & & & & & 10.00 & 8.00 & \\
\hline Soybean meal & 13.28 & 13.21 & 6.00 & 4.00 & 14.20 & 1.60 & & \\
\hline Soybean meal Hipro & & & & 6.00 & & & 11.00 & \\
\hline Soybean oil & 0.38 & & 0.60 & 1.40 & 1.00 & 0.50 & 1.00 & \\
\hline Wheat & 5.00 & 6.00 & 50.24 & 45.71 & 10.00 & 49.89 & 15.00 & \\
\hline Rapeseed cake & 8.00 & 8.00 & & & 8.00 & & & \\
\hline Oats & 25.00 & 30.00 & 1.70 & 3.00 & 9.50 & & 15.00 & \\
\hline Pea starch & 5.00 & & 3.00 & 3.00 & 5.00 & & 6.20 & \\
\hline Limestone & 1.27 & 1.29 & & & & & & \\
\hline Animal fat & 2.00 & 4.03 & 3.20 & 2.10 & 3.00 & 0.70 & 3.00 & \\
\hline Field beans & 5.00 & 2.00 & 3.00 & 3.00 & & 5.00 & 7.00 & \\
\hline Molasses sugar cane & & & 0.70 & 0.50 & 2.00 & 1.00 & 2.00 & \\
\hline Sunflower cake & & & 2.30 & 0.60 & & & & \\
\hline Corn gluten & & & 2.00 & 0.80 & & & & \\
\hline Corn grits & & & & 10.00 & & & & \\
\hline Mikromin Pig & 0.23 & 0.23 & & & & & & \\
\hline Vitamin $A D K B^{b}$ & 0.08 & 0.08 & 0.08 & 0.08 & 0.06 & 0.08 & 0.06 & \\
\hline $\mathrm{mg} / \mathrm{kg}$ & & & & & & & & \\
\hline Sodium selenite (NaSe) & 0.40 & 0.40 & 0.39 & 0.39 & 0.33 & 0.40 & 0.33 & \\
\hline Alpha-tocopherol & 175.00 & 175.00 & 180.00 & 180.00 & 100.00 & 162.00 & 100.00 & \\
\hline
\end{tabular}

The feed composition of the feed provided both MHD cases and controls is listed

$\mathrm{a}, \mathrm{b}$ Additives containing the following per kilogram of diet:

a Fe 96 mg; Cu 20.8 mg; Mn 48 mg; Zn 96 mg; 0.48 mg

bitamin A $5700 \mathrm{IU}$; Vitamin D $1200 \mathrm{IU}$; Vitamin E

100 mg; Vitamin K 3.72 mg; Vitamin B1 2.4 mg; Vitamin B2

$4.5 \mathrm{mg}$; Vitamin B5 $12.0 \mathrm{mg}$; Vitamin B6 $7.2 \mathrm{mg}$; Vitamin

B12 $0.012 \mathrm{mg}$; Folic acid $1.8 \mathrm{mg}$; Biotin $0.24 \mathrm{mg}$

*At Farm 1, the feed was supplemented with whey, accounting for $25 \%$ of the total energy

assessed graphically and model diagnostics were performed.

In all MHD cases, the diagnosis was confirmed by typical macroscopic lesions and histopathological findings. All MHD cases had straw-colored transudate in the pleural and pericardial cavity, often with fibrin strands (Fig. 1). Additionally, pulmonary edema as well as pale and reddened areas of the myocardium due to subepicardial (Fig. 2) and myocardial hemorrhages (Fig. 3) were found. Microscopically, interstitial hemorrhage was observed along with swollen cardiac myofibers that had lost cross striations (Fig. 4). Some histological sections also showed microthrombi, degenerative and necrotic areas with local mineralization.

No lesions were found in skeletal muscles or liver tissues, except MHD case no. 8, also showing macroand microscopic lesions compatible with Hepatosis dietetica.
Based on all ten skeletal muscular samples, mean Se concentrations in MHD cases were 0.34 (0.01) $\mathrm{mg} /$ $\mathrm{kg}$ compared with $0.65(0.02) \mathrm{mg} / \mathrm{kg}$ in control pigs $(P<0.0001)$. Samples from the cardiovascular system showed significantly lower mean Se concentrations in all sampled areas of MHD cases compared with control pigs. Greater difference in mean Se concentrations was observed in the left ventricular wall of the heart; 0.84 $(0.15) \mathrm{mg} / \mathrm{kg}$ vs. $1.13(0.12) \mathrm{mg} / \mathrm{kg}(P=0.0070$, Table 3$)$. If combining the results from the three cardiac samples, the mean Se concentration in MHD cases was $0.87(0.02)$ $\mathrm{mg} / \mathrm{kg}$ as opposed to $1.12(0.04) \mathrm{mg} / \mathrm{kg}(P<0.0001)$ in the cardiac samples from controls.

Within the digestive system, lower average Se concentrations were found in samples from the MHD cases' gastric ventricle, duodenum, jejunum and caecum. In the liver samples, mean Se concentrations of MHD cases were $1.29(0.20) \mathrm{mg} / \mathrm{kg}$ vs $1.77 \mathrm{mg} / \mathrm{kg}(0.40)$ in controls 


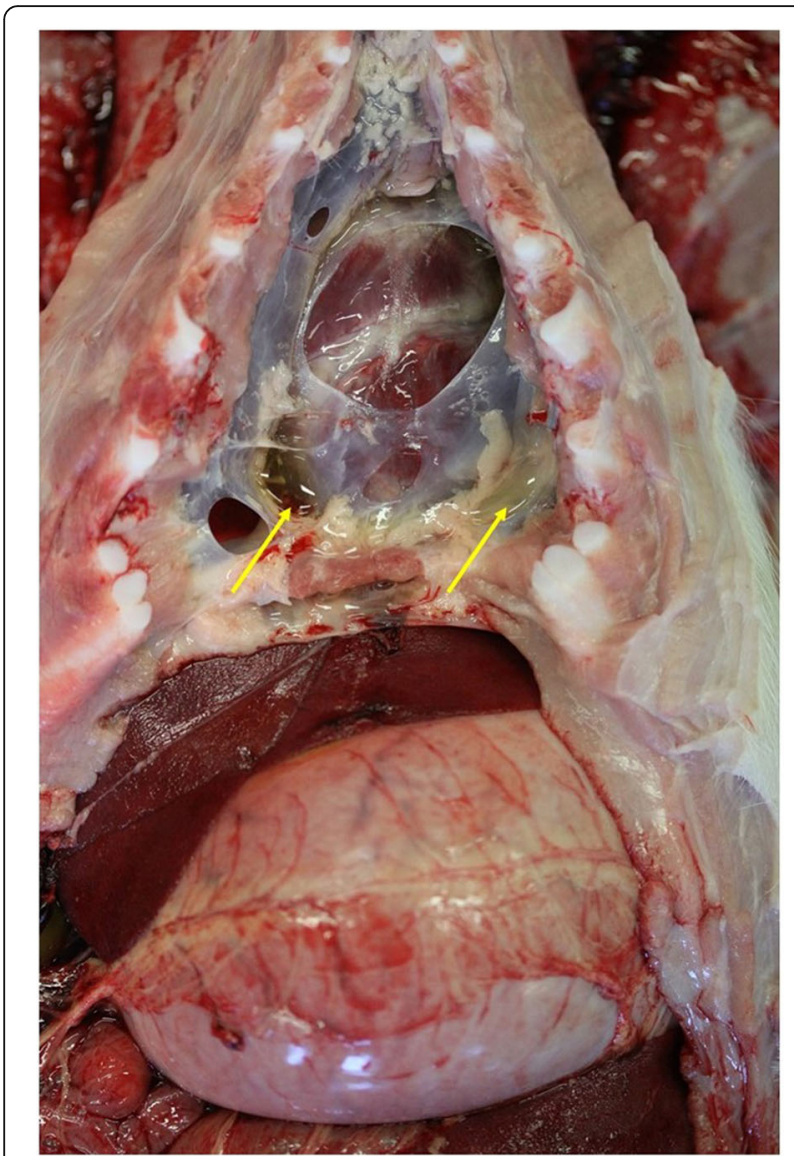

Fig. 1 Transudate in the pleural cavity

$(P=0.020)$. No differences between MHD cases and controls were found in samples from the adrenal glands, claws, colon, ileum, lungs, lymph nodes, pancreas, parathyroid gland, spleen or thyroid gland.

\section{Discussion and conclusions}

The sampled pigs in this report constitute a heterogenous group since multiple genetic lines fed different feed and pigs with differing bodyweight are represented. These are factors potentially influencing the pigs' susceptibility to oxidative stress and MHD. We find it interesting that although our limited number of sampled pigs are different in terms of genetics, size and feeding regimes, the variation of $\mathrm{Se}$ concentrations in a given organ is low between MHD cases.

The results from this study provide information about the Se distribution both in internal and external organs in MHD cases and designates muscle tissue as particularly interesting regarding the diagnostic approach. Most reports describing pigs with MHD refer to vitamin $E$ and Se concentrations in liver samples [10, 18-20, 23]. Although biodilution

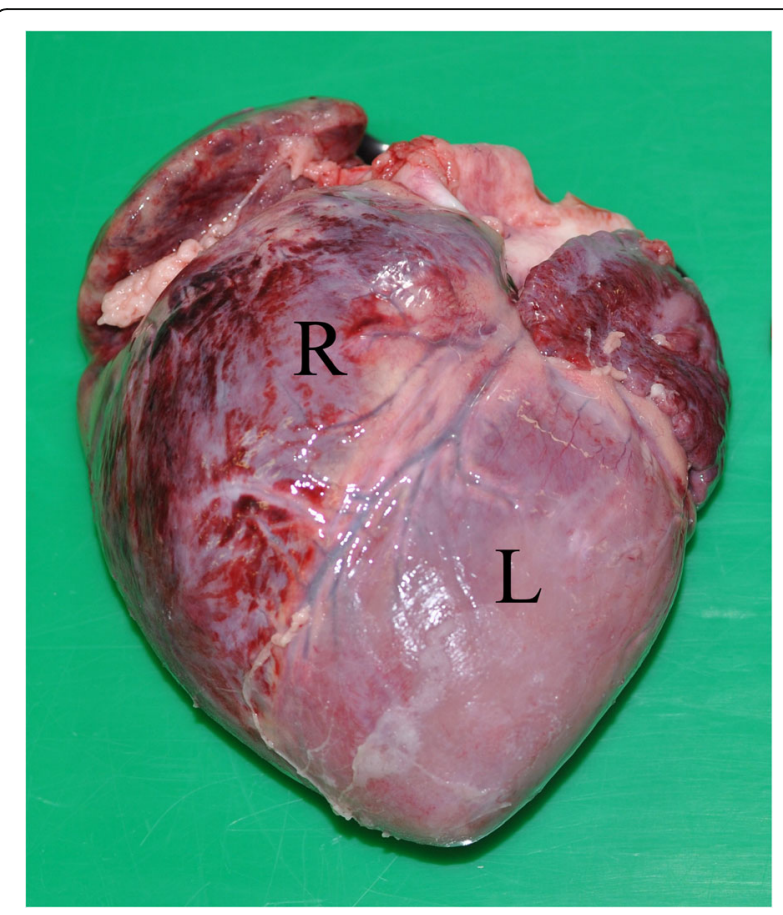

Fig. 2 Subepicardial hemorrhages

cannot be excluded (difference in weight and age), our results did render significant differences in liver Se concentrations between MHD cases and control animals. Mean liver concentrations of MHD cases (dry basis) in this study were $1.29 \mathrm{mg} / \mathrm{kg}(0.20)$. A liver concentration of $1.2 \mathrm{mg} \mathrm{Se} / \mathrm{kg}$ (dry basis) was suggested by Lindberg and Siren as normal [24]. Other studies have stated that MHD cases apparently show Se liver concentrations within what is considered the normal range $[10,19]$. Thus, the questions arise if the Se concentrations in liver samples from healthy, high-yielding pigs of today should actually be higher, if other samples should be collected and analyzed, and if genetic differences between breeds could affect the actual Se requirements. A recent study has shed light on the micronutrient-genetic relationships and showed that genetic background can affect the intake of minerals [25]. Typically MHD cases are pigs growing rapidly. This feature combined with possible individual disparities regarding feed intake and efficiency may contribute to a disruption in proper mineral intake and cause certain individuals within a group of pigs to succumb to MHD.

Most previous reports on MHD also include Se concentrations in myocardial samples, which is reasonable since pathological findings are found invariably in the myocardium of MHD cases. Here, a significant difference was found between MHD samples and controls 
Table 3 Se concentrations in different organ samples from cases of Mulberry Heart Disease (MHD) and controls (mg/ kg dry weight)

\begin{tabular}{|c|c|c|c|c|c|c|}
\hline \multirow[t]{2}{*}{ Organ system } & \multirow[t]{2}{*}{ Organ samples } & \multicolumn{2}{|l|}{$\mathrm{MHD}$} & \multicolumn{2}{|l|}{ Control } & \multirow[t]{2}{*}{$P$-value } \\
\hline & & Mean Se (mg/ kg) & $n$ & Mean Se (mg/ kg) & $n$ & \\
\hline \multirow[t]{3}{*}{ Cardiovascular system } & Myocardium, left ventricle & $0.84(0.15)$ & 8 & $1.13(0.12)$ & 3 & 0.0070 \\
\hline & Myocardium, right ventricle & $0.92(0.04)$ & 5 & $1.11(0.15)$ & 3 & 0.032 \\
\hline & Myocardium, septum & $0.88(0.04)$ & 6 & $1.16(0.06)$ & 3 & 0.0059 \\
\hline \multirow[t]{8}{*}{ Digestive system } & Caecum & $0.63(0.11)$ & 8 & $0.87(0.18)$ & 3 & 0.020 \\
\hline & Colon & $0.77(0.19)$ & 8 & $1,04(0.23)$ & 3 & ns \\
\hline & Duodenum & $0.78(0.15)$ & 7 & $1.20(0.10)$ & 3 & 0.0020 \\
\hline & Gastric ventricle & $0.64(0.13)$ & 6 & $0.93(0.08)$ & 3 & 0.0090 \\
\hline & lleum & $0.86(0.11)$ & 8 & $1.04(0.20)$ & 3 & ns \\
\hline & Jejunum & $0.90(0.14)$ & 8 & $1.27(0.15)$ & 3 & 0.0040 \\
\hline & Liver & $1.29(0.20)$ & 8 & $1.77(0.40)$ & 3 & 0.020 \\
\hline & Pancreas & $1.01(0.28)$ & 7 & $1.18(0.57)$ & 3 & ns \\
\hline \multirow[t]{7}{*}{ Immune and endocrine system } & Ln ileocolici & $1.07(0.42)$ & 8 & $1.43(0.16)$ & 3 & ns \\
\hline & Ln poplitei & $0.78(0.27)$ & 8 & $0.70(0.13)$ & 3 & ns \\
\hline & Parathyroid gland & $0.88(0.33)$ & 5 & $0.80(0.16)$ & 3 & ns \\
\hline & Spleen & $1.18(0.17)$ & 5 & $1.33(0.06)$ & 3 & ns \\
\hline & Thymus & $0.97(0.06)$ & 8 & $1.16(0.15)$ & 3 & 0.012 \\
\hline & Thyroid gland & $0.64(0.13)$ & 7 & $0.79(0.12)$ & 3 & ns \\
\hline & Adrenal gland & $1.20(0.08)$ & 5 & $1.20(0.10)$ & 3 & ns \\
\hline \multirow[t]{2}{*}{ Integumentary } & Claw & $0.41(0.12)$ & 5 & $0.66(0.25)$ & 3 & ns \\
\hline & Skin & $0.14(0.02)$ & 7 & $0.25(0.07)$ & 3 & 0.0041 \\
\hline \multirow[t]{10}{*}{ Muscular system } & Diaphragm & $0.39(0.10)$ & 6 & $0.62(0.11)$ & 3 & 0.020 \\
\hline & M. biceps brachii & $0.35(0.09)$ & 8 & $0.64(0.17)$ & 3 & 0.0040 \\
\hline & M. extensor carpi radialis & $0.34(0.07)$ & 8 & $0.66(0.19)$ & 3 & 0.0020 \\
\hline & M. extensor digitorum longus & $0.33(0.07)$ & 8 & $0.65(0.17)$ & 3 & 0.0010 \\
\hline & M. longissimus dorsi lumbalis & $0.35(0.05)$ & 5 & $0.62(0.24)$ & 3 & 0.042 \\
\hline & M. longissimus dorsi thobaracis & $0.43(0.23)$ & 8 & $0.66(0.25)$ & 3 & ns \\
\hline & M. psoas major & $0.34(0.08)$ & 8 & $0.67(0.21)$ & 3 & 0.0028 \\
\hline & M. quadriceps femoris & $0.33(0.08)$ & 7 & $0.68(0.22)$ & 3 & 0.0040 \\
\hline & M. semimembranosus & $0.32(0.08)$ & 8 & $0.64(0.18)$ & 3 & 0.0018 \\
\hline & M. semitendinosus & $0.28(0.05)$ & 8 & $0.62(0.20)$ & 3 & 0.0011 \\
\hline Respiratory system & Lung & $0.96(0.23)$ & 8 & $1.23(0.06)$ & 3 & ns \\
\hline Urinary system & Kidney & $4.93(0.57)$ & 7 & $6.23(1.07)$ & 3 & 0.030 \\
\hline
\end{tabular}

Se concentrations in internal and external samples from MHD and control pigs. Results are based on dry weight analyses

with respect to the samples isolated from the septum $(P<0.01)$, left $(P<0.01)$ and right ventricle $(P<0.05)$ of the myocardium. This is not in accordance with previous studies, reporting no difference between MHD cases and controls in terms of Se concentrations in cardiac samples $[18,26]$. In a recent publication the authors stated that different muscle tissues have distinct intrinsic mitochondrial respiratory functions, which likely influences the efficiency of oxidative phosphorylation and could potentially alter reactive oxygen species (ROS) production
[27] .The cardiac muscle with its high metabolic demand is rich in mitochondria, accounting for approximately $35 \%$ of the cardiac tissue volume. Skeletal muscles exhibit approximately half of the mitochondrial density found in the cardiac muscle. Since mitochondria are the most important cellular source of ROS [28], this may contribute to the cardiac muscle susceptibility to ROSinduced oxidative injury if a pig is deficient in antioxidant factors. A rodent Se deficiency and repletion model showed a distinct distribution of selenoenzymes, 


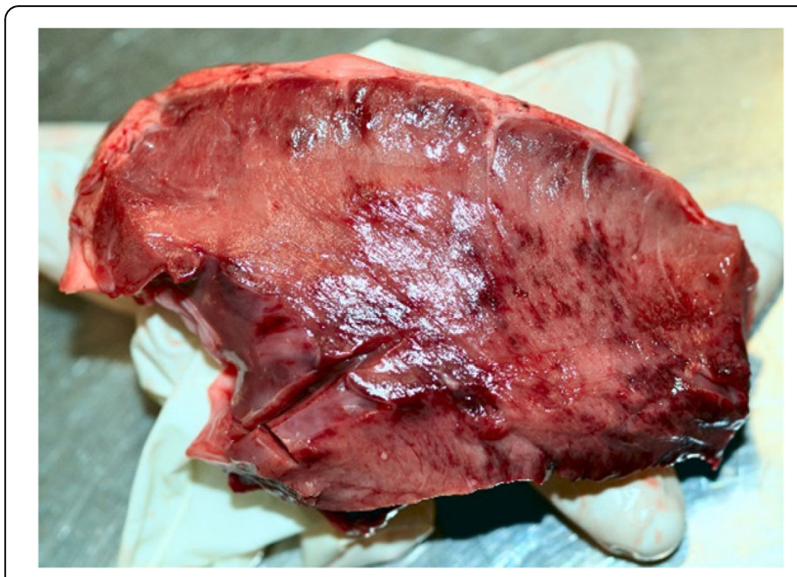

Fig. 3 Myocardial hemorrhages

suggesting that the heart may be the organ most sensitive to oxidative stress [29]. The fact that all MHD cases showed macroscopic and microscopic lesions in cardiac samples but not in skeletal muscles may support this theory. Within the cardiac muscle, some areas may be of particular importance for sampling, like the papillary muscles. They are located in both ventricles of the heart and it has been shown that papillary muscles are prone to fibrosis upon oxidative stress insults [30]. A more standardized approach for sampling of the cardiac muscle of MHD cases may contribute to less interindividual variability regarding Se concentrations.

In industrialized pork production, feed costs account for approximately 60 to $70 \%$ of the total production costs [16, 17, 31, 32]. Since higher economic outputs of pork production can be achieved by improved feed efficiency, selection for high lean growth rate and reduced backfat, commercial pig lines have been systematically bred over decades to improve these traits $[15,33,34]$. Norsvin is a breeding company owned by Norwegian pig producers with a research department at the Norwegian University of

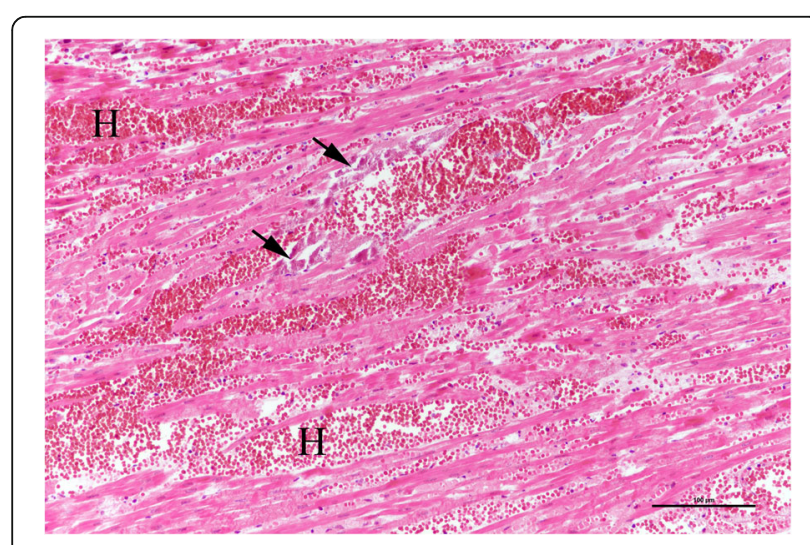

Fig. 4 Interstitial hemorrhages
Life Sciences (NMBU). The breeding program pursued by Norsvin has e.g. led to a reduction in necessary feed per $\mathrm{kg}$ of weight gain and increased average daily gain (ADG) in weaned pigs and grower-finishers over the last ten years [35, 36]. In 2007, Norwegian conventional weaned pigs (typically DLYL, LLLL or YYLL) between approximately 10 and $30 \mathrm{~kg}$ live weight (LW) showed ADG of $489 \mathrm{~g}$ vs. $582 \mathrm{~g}$ in 2017. Grower-finishers between approximately $30 \mathrm{~kg}$ and $115 \mathrm{~kg}$ LW showed an ADG of $955 \mathrm{~g}$ in $2007 \mathrm{vs}$. $1018 \mathrm{~g}$ in 2017 (Table 4). During the same time period (2007 to 2017), the amount of feed per unit gain was reduced in both weaned pigs (1.81 to 1.71 ) and grower-finishers (2.74 to 2.68). The lean meat percentage in finisher pigs rose from 56.5 to $59.8 \%$. Typically, Norwegian pig feed is added between 0.35 and $0.40 \mathrm{mg} \mathrm{Se} / \mathrm{FU}$, both for weaned and growerfinisher pigs (until recently the dominating Se source has been inorganic sodium selenite). This means that during the last decade, there has been a reduction in available Se. This is due to the reduced amount of necessary feed per unit weight gain and the concurrent increase in body protein deposition, possibly contributing to the occurrence of MHD.

Several authors have considered the theory of resource allocation in lean and feed efficient pigs, which is built on the assumption that different biological processes require different nutritional resources [3740]. The systematic selection for leaner pigs over decades may have led to a trade-off towards growth in situations where nutritional resources are scarce. Processes involving e.g. the immune and antioxidative status of the animal can thereby be weakened and result in pigs more susceptible to oxidative assaults. Our results showing significantly lower Se concentrations in samples from the thymus of MHD cases may strengthen this theory.

Table 4 Development of Norwegian pig production results from 2007 to 2017

\begin{tabular}{llll}
\hline Production trait & Age group & \multicolumn{2}{l}{ Year } \\
\cline { 3 - 4 } & & 2007 & 2017 \\
\hline Average daily weight gain (g/ day) & Weaned pigs & 489 & 582 \\
& Grower-finisher pigs & 955 & 1018 \\
Feed units per kg gain (FU/ kg) & Weaned pigs & 1.81 & 1.71 \\
& Grower-finisher pigs & 2.74 & 2.68 \\
Lean meat percentage (\%) & Grower-finisher pigs & 56.50 & 59.80
\end{tabular}

The numbers origin from the annual Ingris report, an online tool available for both Norwegian breeding (nucleus and multiplier) herds as well as piglet producing and finisher units. In 2007, 35\% of sow farms and $3.1 \%$ of finisher farms were represented in the Ingris annual report. In $2017,54 \%$ of sow farms and $12.3 \%$ of finisher farms were represented. In the Norwegian pig production system, weaned pigs are between approximately $10 \mathrm{~kg} \mathrm{LW}$ and 30 kg LW. Grower-finishers are between approximately $30 \mathrm{~kg} \mathrm{LW}$ and $115 \mathrm{~kg} \mathrm{LW}$ 
The MHD cases showed significantly lower mean Se concentrations in the samples from the gastric ventricle $(P<0.01)$, the duodenum $(P<0.005)$, jejunum $(P<0.005)$ and caecum $(P<0.05)$. These findings may partly be explained by the absorption pattern of Se in the intestinal tract. In swine, more Se is absorbed in the last part of the small intestine, cecum and colon than in the stomach and proximal parts of the small intestine [41]. Oxidative stress is a major cause of gastrointestinal (GI) damage [42] and robust immunologic mechanisms are required to protect the mucosal surface. The Se dependent glutathione peroxidase GSHPx-GI appears to be the major glutathionedependent peroxidase in the GI tract and this molecule could play a major role in protecting mammals from the toxicity of ingested lipid hydroperoxides [43, 44]. Se dependent glutathione peroxidase is expressed at lower concentrations when the organism enters Se deficiency [45]. A possible explanation to our Se measurements in the proximal parts of the GI tract may therefore be a lower absorption of $\mathrm{Se}$ in proximal intestinal segments combined with lower expression of GSHPx-GI in MHD cases than controls. Less difference in Se levels between MHD cases and controls were found in caecum and colon. Significantly lower mean Se concentrations in skin $(P<0.005)$ and kidney $(P<0.05)$ samples from MHD cases were found, probably due to lowered selenoprotein expression during Se deficiency $[46,47]$.

No vitamin $E$ analyses were included in this study due to budget limitations. Previous results have indicated that pigs with MHD have lower tissue alphatocopherol concentrations than the control pigs [26], and therefore its role in the pathogenesis of MHD needs further elucidation [2]. The trace elements calcium, copper, zinc, magnesium, iron would have been interesting to add to the analyses, since it has previously been described that Se deficiency can alter the distribution of other minerals $[48,49]$.

In other animals, like cattle, the Se requirements are differentiated according to muscularity [50]. The question whether lean, feed efficient pigs have higher Se requirements than slower growing pigs with a lower lean meat percentage is indeed worthwhile pursuing.

In conclusion, this study shows discrepancies in tissue Se concentrations between MHD cases and controls. As mentioned initially, the common practice regarding collection of samples from MHD cases in the field could be extended to include samples from the diaphragm or skeletal muscles for Se analysis, since these organ samples are easy accessible during field necropsy. Although the variation in Se concentrations of a given organ between MHD cases of different genetic origin and age was low, this report includes a limited number of pigs. Therefore our results should be affirmed by a larger randomized controlled trial.

\section{Abbreviations}

(ICP-MS): Inductively coupled plasma mass spectrometry; DM: Dry matter; GSHPX-GI: Intestinal form of glutathione peroxidase; HE: Hematoxylin and eosin; MHD: Mulberry Heart Disease; Q: Quadropoles; Se: Selenium; Te: Tellurium

\section{Acknowledgements}

We wish to thank the farmers for submitting MHD cases and control animals. Determination of Se is performed at NMBU/MINA and we will thank Susanne Birkeland for technical support. Part of the work is also supported by the Research Council of Norway through its Centres of Excellence funding scheme, project number 223268/F50.

\section{Authors' contributions}

MOM, MF, BS, HW, AB and TF planned the study. MF, MOM and HW carried out necropsies and sample isolation. MV and BS were responsible for the selenium analyses. MOM drafted the manuscript. All authors read, commented on, and approved the final manuscript.

\section{Funding}

This study was supported by the Norwegian Levy on Agricultural Products (FFL), the Agricultural Agreement Research Fund of Norway (JA) and the Centre of Excellence (CoE) Centre of Environmental Radiology, funding scheme (Project No. 223268/F50), NMBU - MINA/CERAD, Ås, Norway.

\section{Availability of data and materials}

The data generated during the current case report are kept and stored by the corresponding author. The data are available from the corresponding author on reasonable request.

\section{Ethics approval}

No ethics approval was necessary since this case report describes diagnostic approaches and sampling procedures conducted by the veterinary pathologists during their search for the cause of sudden deaths in the pigs of the case herd.

\section{Consent for publication}

The farmers gave their consent to publish the results from the analyses of samples originating from their pigs.

\section{Competing interests}

The authors declare that they have no competing interests.

\section{Author details}

${ }^{1}$ Department of Production Animal Clinical Sciences, Norwegian University of Life Sciences, 4325 Sandnes, Norway. ${ }^{2}$ Norwegian Veterinary Institute, 4325 Sandnes, Norway. ${ }^{3}$ Faculty of Environmental Sciences and Nature Resource Management (MINA)/CERAD CoE, Norwegian University of Life Sciences, $1430 \AA ̊$ As, Norway. ${ }^{4}$ Norwegian Veterinary Institute, 0106 Oslo, Norway. ${ }^{5}$ Department of Production Animal Clinical Sciences, Norwegian University of Life Sciences, 0454 Oslo, Norway.

Received: 4 March 2019 Accepted: 14 June 2019

Published online: 01 September 2019

References

1. Lingaas F, Brun E, Frøslie A. Estimates of heritability for selenium and glutathione peroxidase levels in pigs. J Anim Breed Genet. 1990;108:48-53.

2. Grant Maxie M, Robinson WF. In: Anim PD, editor. Mulberry heart disease of swine. 6th ed. London, UK: Elsevier; 2016. p. 39-41.

3. Loynachan AT. Mulberry heart disease. Dis swine. 10th ed. West Sussex, UK: Wiley-Blackwell Publishing Ltd; 2012. p. 192-3.

4. Falk M, Bernhoft A, Framstad T, Salbu B, Wisløff H, Kortner TM, et al. Effects of dietary sodium selenite and organic selenium sources on immune and inflammatory responses and selenium deposition in growing pigs. J Trace Elem Med Biol. 2018;50:527-36

5. Rederstorff $M$, Krol A, Lescure A. Understanding the importance of selenium and selenoproteins in muscle function. Cell Mol Life Sci. 2006;63:52-9.

6. Whanger PD, Vendeland SC, Beilstein MA. Trace Elem Man Anim TEMA 8. Gersdorf, Germandy: Verlag Media Touristik; 1993. p. 119-26. 
7. Jeong D, Kim TS, Chung YW, Lee BJ, Kim IY. Selenoprotein W is a glutathione-dependent antioxidant in vivo. FEBS Lett. 2002;517:225-8.

8. Yang JG, Hill KE, Burk RF. Dietary selenium intake controls rat plasma selenoprotein P concentration. J Nutr. 1989;119:1010-2.

9. Beckendorf $L$, Linke WA. Emerging importance of oxidative stress in regulating striated muscle elasticity. J Muscle Res Cell Motil. 2015;36:25-36.

10. Pallarés FJ, Yaeger MJ, Janke BH, Fernández G, Halbur PG. Vitamin E and selenium concentrations in livers of pigs diagnosed with mulberry heart disease. J Vet Diagn Investig Off Publ Am Assoc Vet Lab Diagn Inc. 2002;14:412-4.

11. Archibald AL, Bolund L, Churcher C, Fredholm M, Groenen MAM, Harlizius B, et al. Pig genome sequence--analysis and publication strategy. BMC Genomics. 2010;11:438.

12. Wijga S, Broekhuijse M, Gaustad AH, Duijvesteijn N, Grindflek E. Groundbreaking research for maximum genetic progress. Topigs Norsvin Annu Mag. 2016:58-61.

13. Cameron ND, Curran MK. Selection for components of efficient lean growth rate in pigs 4. Genetic and phenotypic parameter estimates and correlated responses in performance test traits with ad-libitum feeding. Anim Sci. 1994; 59:281-91.

14. Kerr JC, Cameron ND. Reproductive performance of pigs selected for components of efficient lean growth. Anim Sci. 1995;60:281-90.

15. Lonergan SM, Huff-Lonergan E, Rowe $L$, Kuhlers DL, Jungst SB. Selection for lean growth efficiency in Duroc pigs influences pork quality. J Anim Sci. 2001;79:2075-85.

16. Martinsen $\mathrm{KH}$, Olsen D, Ødegård J, Meuwissen T. Economic values for lean meat and fat efficiency in Norwegian landrace nucleus pig population. Acta Agric Scand Sect — Anim Sci. 2016;66:145-51.

17. Patience JF, Rossoni-Serão MC, Gutiérrez NA. A review of feed efficiency in swine: biology and application. J Anim Sci Biotechnol. 2015;6:33.

18. Shen H, Thomas PR, Ensley SM, Kim W-I, Loynachan AT, Halbur PG, et al. Vitamin $E$ and selenium levels are within normal range in pigs diagnosed with mulberry heart disease and evidence for viral involvement in the syndrome is lacking. Transbound Emerg Dis. 2011;58:483-91.

19. Nielsen TK, Wolstrup C, Schirmer AL, Jensen PT. Mulberry heart disease in young pigs without vitamin E and selenium deficiency. Vet Rec. 1989;124: 535-7.

20. Korpela $\mathrm{H}$. Hepatic selenium concentration in pigs with microangiopathy (mulberry heart disease)--an animal model for the study of oxidative damage. Int J Vitam Nutr Res Int Z Vitam- Ernahrungsforschung J Int Vitaminol Nutr. 1990;60:156-8.

21. Sharp BA, Young LG, van DAA. Dietary induction of mulberry heart disease and Hepatosis Dietetica in pigs I. nutritional aspects. Can J Comp Med. 1972:36:371-6.

22. Brandt-Kjelsen A, Govasmark E, Haug A, Salbu B. Turnover of se in adequately fed chickens using se-75 as a tracer. J Anim Physiol Anim Nutr 2014:98:547-58

23. Moir DC, Masters HG. Hepatosis dietetica, nutritional myopathy, mulberry heart disease and associated hepatic selenium level in pigs. Aust Vet J. 1979:55:360-4

24. Lindberg P, Siren M. Fluorometric selenium determination in the liver of normal pigs affected with nutritional muscular dystrophy and liver dystrophy. Acta Vet Scand. 6:59-64

25. Liu J, Tuvblad C, Raine A, Baker L. Genetic and environmental influences on nutrient intake. Genes Nutr. 2013:8:241-52.

26. Rice DA, Kennedy S. Vitamin E, selenium, and polyunsaturated fatty acid concentrations and glutathione peroxidase activity in tissues from pigs with dietetic microangiopathy (mulberry heart disease). Am J Vet Res. 1989:50:2101-4.

27. Park S-Y, Gifford JR, Andtbacka RHI, Trinity JD, Hyngstrom JR, Garten RS, et al. Cardiac, skeletal, and smooth muscle mitochondrial respiration: are all mitochondria created equal? Am J Physiol - Heart Circ Physiol. 2014;307: H346-52.

28. Boengler K, Kosiol M, Mayr M, Schulz R, Rohrbach S. Mitochondria and ageing: role in heart, skeletal muscle and adipose tissue. J Cachexia Sarcopenia Muscle. 2017:8:349-69.

29. Weitzel F, Ursini F, Wendel A. Phospholipid hydroperoxide glutathione peroxidase in various mouse organs during selenium deficiency and repletion. Biochim Biophys Acta BBA - Gen Subj. 1990;1036:88-94.

30. Aragno M, Mastrocola R, Alloatti G, Vercellinatto I, Bardini P, Geuna S, et al. Oxidative stress triggers cardiac fibrosis in the heart of diabetic rats. Endocrinology. 2008;149:380-8.
31. Rocadembosch J, Amador J, Bernaus J, Font J, Fraile LJ. Production parameters and pig production cost: temporal evolution 2010-2014. Porc Health Manag [Internet. 2016;2 Available from: https://www.ncbi.nlm.nih. gov/pmc/articles/PMC5382395/.

32. Mauch $E$. The genetic basis of feed efficiency in swine divergently selected for residual feed intake. [lowa, USA]: Iowa State University capstones; 2018.

33. Bereskin B, Hetzer HO. Genetic and maternal effects on pig weights, growth and probe backfat in diallel crosses of high- and low-fat lines of swine. J Anim Sci. 1986:63:395-408.

34. Gjerlaug-Enger $E$, Aass L, Odegård J, Vangen O. Genetic parameters of meat quality traits in two pig breeds measured by rapid methods. Anim Int J Anim Biosci. 2010;4:1832-43.

35. Animalia, Norsvin. Ingris Årsstatistikk 2017 [Internet]. Norway; 2018. Report no.: 2018. Available from: https://www.animalia.no/contentassets/ 28e0db72674d496186f0570a9e606fca/arsstatistikk_2017.pdf

36. Animalia N. Ingris Årsstatistikk 2011 [Internet]. Norway; 2012. Report No.: 2011. Available from: https://www.animalia.no/contentassets/ 28e0db72674d496186f0570a9e606fca/arsstatistikk-2011.pdf

37. Beilharz RG, Luxford BG, Wilkinson JL. Quantitative genetics and evolution: is our understanding of genetics sufficient to explain evolution? J Anim Breed Genet Z Tierzuchtung Zuchtungsbiologie. 1993;110:161-70.

38. van der Waaij $\mathrm{EH}$. A resource allocation model describing consequences of artificial selection under metabolic stress. J Anim Sci. 2004;82:973-81.

39. Doeschl-Wilson AB, Kyriazakis I, Vincent A, Rothschild MF, Thacker E, GalinaPantoja L. Clinical and pathological responses of pigs from two genetically diverse commercial lines to porcine reproductive and respiratory syndrome virus infection. J Anim Sci. 2009;87:1638-47.

40. Rauw WM, Kanis E, Noordhuizen-Stassen EN, Grommers FJ. Undesirable side effects of selection for high production efficiency in farm animals: a review. Livest Prod Sci. 1998;56:15-33.

41. Wright PL, Bell MC. Comparative metabolism of selenium and tellurium in sheep and swine. Am J Phys. 1966;211:6-10

42. Suzuki H, Matsuzaki J, Hibi T. Ghrelin and oxidative stress in gastrointestinal tract. J Clin Biochem Nutr. 2011;48:122-5.

43. Chu FF, Esworthy RS. The expression of an intestinal form of glutathione peroxidase (GSHPx-GI) in rat intestinal epithelium. Arch Biochem Biophys. 1995:323:288-94.

44. Chu FF, Doroshow JH, Esworthy RS. Expression, characterization, and tissue distribution of a new cellular selenium-dependent glutathione peroxidase, GSHPx-GI. J Biol Chem. 1993;268:2571-6.

45. Burk RF. Molecular biology of selenium with implications for its metabolism. FASEB J Off Publ Fed Am Soc Exp Biol. 1991:5:2274-9.

46. Tsuji PA, Carlson BA, Anderson CB, Seifried HE, Hatfield DL, Howard MT. Dietary selenium levels affect Selenoprotein expression and support the interferon- $\gamma$ and IL-6 immune response pathways in mice. Nutrients. 2015;7: 6529-49.

47. Malinouski M, Kehr S, Finney L, Vogt S, Carlson BA, Seravalli J, et al. Highresolution imaging of selenium in kidneys: a localized selenium Pool associated with glutathione peroxidase 3. Antioxid Redox Signal. 2012;16: 185-92.

48. Chareonpong-Kawamoto N, Yasumoto K. Selenium deficiency as a cause of overload of iron and unbalanced distribution of other minerals. Biosci Biotechnol Biochem. 1995;59:302-6.

49. Zhang Z, Liu M, Guan Z, Yang J, Liu Z, Xu S. Disbalance of calcium regulation-related genes in broiler hearts induced by selenium deficiency. Avian Pathol J WVPA. 2017;46:265-71

50. Mehdi Y, Dufrasne I. Selenium in cattle: a review. Molecules. 2016;21.

\section{Publisher's Note}

Springer Nature remains neutral with regard to jurisdictional claims in published maps and institutional affiliations. 